\title{
Brave New World of Conservation Paleobiology
}

\author{
Gregory P. Diet/ ${ }^{1,2 *}$ \\ ${ }^{1}$ Paleontological Research Institution, Ithaca, NY, USA, ${ }^{2}$ Department of Earth and Atmospheric Sciences, Cornell University, \\ Ithaca, NY, USA
}

Keywords: conservation biology, cross-disciplinary, environmental ethics, environmental philosophy, geohistorical data, normative postulates, values

\section{OPEN ACCESS}

Edited by:

G. Lynn Wingard,

United States Geological Survey, USA

Reviewed by:

Michal Kowalewski, University of Florida, USA

Thomas Eugene Lovejoy,

George Mason University, USA

${ }^{*}$ Correspondence:

Gregory P. Diet

gpd3@cornell.edu

Specialty section:

This article was submitted to

Paleoecology,

a section of the journal

Frontiers in Ecology and Evolution

Received: 29 January 2016

Accepted: 26 February 2016

Published: 16 March 2016

Citation:

Dietl GP (2016) Brave New World of

Conservation Paleobiology.

Front. Ecol. Evol. 4:21.

doi: 10.3389/fevo.2016.00021
Conservation paleobiology is a rapidly developing, socially relevant field that uses information from geohistorical records to address current problems in the conservation and restoration of biodiversity and ecosystem services (Dietl et al., 2015). Over the past decade, the field has achieved critical mass-filling an empty niche in the conservation landscape-with the beginnings of a core literature, regular symposia and workshops at professional meetings, and the training of the first generation of students who identify themselves as conservation paleobiologists. However, this period of rapid growth has occurred without explicit acknowledgment and expression of the assumptions that define the young field and unite its practitioners. Here, I open a discussion about the central role of values in conservation paleobiology.

A logical place to start is by asking how values fit into the field of conservation biology. Conservation biology emerged in the 1980's as a field defined by its goal: biodiversity preservation. Thus, conservation biology is inherently based on a normative standard-that is, it makes the claim (or value judgment) that biodiversity is something good and thus worth being preserved. It is this value-laden nature of conservation biology that makes it conceptually distinct as a field (Soule, 1985; Barry and Oelschlaeger, 1996). By asserting the identity of conservation biology as a "value-laden, mission-driven science," conservation biologists committed to having to justify why biodiversity should or ought to be conserved (Van Dyke, 2008).

Two broad ethical positions have long motivated conservation action (Soule, 1985; Kareiva and Marvier, 2012; Hunter et al., 2014). Some conservation biologists embrace the claim that biodiversity has intrinsic value. Accepting the intrinsic value of biodiversity means that species have value independent of human interests. Thus, people have an ethical and moral responsibility to protect biodiversity, regardless of whether such action benefits humans. Conservation is also motivated by a range of more anthropocentric concerns, particularly the instrumental value (usefulness) of biodiversity in providing goods or services to people (e.g., food security or clean water).

These different views invite debate-as recent polemic about the "new conservation" illustrates (Tallis and Lubchenco, 2014)-because the acceptance of either value framework influences what counts as conservation and the way conservation policy is conceptualized and formulated. Nevertheless, conservation biologists understand that values are the engine of conservation action (Van Dyke, 2008). If conservation biologists didn't ground their work in a clear value system, they would be left with no argument for why we should preserve biodiversity and support for conservation would be difficult to secure.

Conservation paleobiology should be no different. If we look closely at the definition of conservation paleobiology that opened this essay, we see that it too is defined by its goal: the conservation and restoration of biodiversity and ecosystem services. Thus, conservation paleobiology inescapably has a normative component in addition to a descriptive one. Conservation paleobiology is built on the value assumption that biodiversity and ecosystem services are good and ought to be conserved (or restored). Put another way, at its core, the idea of 


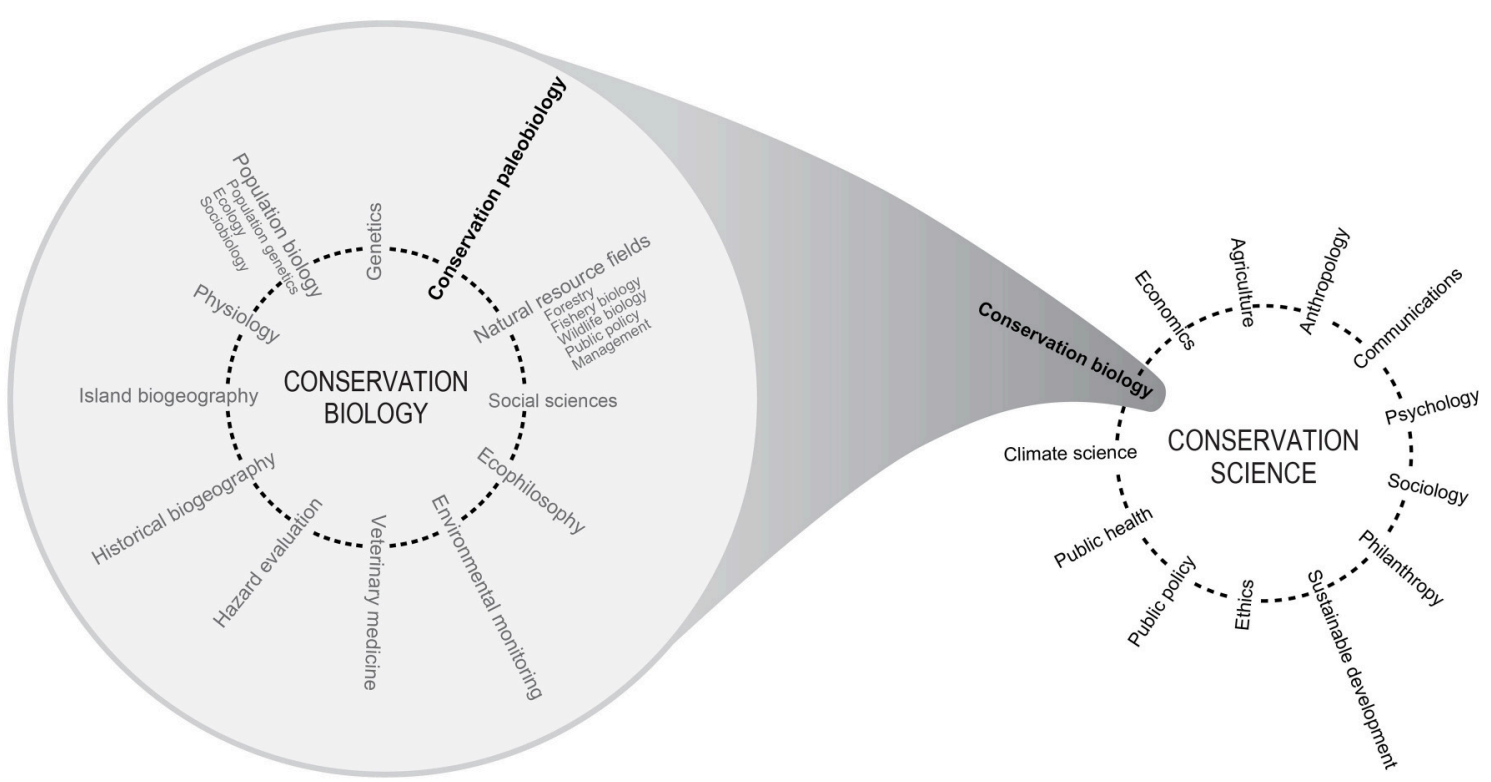

FIGURE 1 | The expanding domain of conservation science. The left diagram illustrates the contribution of conservation paleobiology to Soule's (1985) synthetic, cross-disciplinary conservation biology. The diagram on the right depicts how Soule's conservation biology fits into Kareiva and Marvier's (2012) broader view of conservation science. Adapted from Peter Kareiva and Michelle Marvier, What Is Conservation Science? BioScience (2012) 62(11):962-969, by permission of the American Institute of Biological Sciences.

conservation paleobiology is to mobilize the collective expertise in the paleontological sciences around a common purpose (the conservation and restoration of biodiversity and ecosystem services).

The definition of conservation paleobiology also shares values with both conservation biologists who support protecting biodiversity for its instrumental value to our own lives and those who argue that biodiversity should be protected for its own sake (or intrinsic value). This intentional appeal to value pluralism recognizes that the goal of preserving the diversity of life can be accomplished without commitment to a single value system. In other words, different conservation contexts often demand different strategies and different ethical justifications (Robinson, 2010).

This inherently normative aspect (present at the birth of the field) makes conservation paleobiology distinctly different from traditional paleobiology, and forces a critical choice to be made, one that will determine-to a large extent-the overall success of the approach. I envision two possible futures for conservation paleobiology: the field can take a familiar path and remain a closed discussion among paleontologists insulated from the normative concerns of conservation biology; or, it can choose a less familiar path, one that aligns with conservation biology (Figure 1) and explicitly acknowledges its normative structure.

I think taking the familiar path is the wrong direction. Without openly acknowledging its normative basis, conservation paleobiology risks turning inwards, becoming an undirected and insular academic discourse about paleontologically interesting problems. In the long run, this orientation will weaken not strengthen the field. A normative vacuum impoverishes the field by rendering it functionally sterile, ultimately providing little tangible influence in the "real world" of conservation policy and management.

To avoid marginalization, conservation paleobiologists must take an active interest in and reflection on the normative underpinnings of their science. Every conservation paleobiologist must have an awareness of the explicit values upon which conservation stands. Bringing values into conservation paleobiology does not mean, however, that scientific credibility is sacrificed. A value-driven conservation paleobiology retains its scientific legitimacy as long as we remain committed to the ethical norms of science, the most basic of which are honesty and integrity (Lovejoy, 1989).

As we begin to navigate this brave new world of conservation paleobiology, we should take some inspiration in knowing that we are not alone. The depth of conservation biology's internal disagreement about which value system(s) should motivate conservation action runs deep (Van Dyke, 2008), but this tension also gives the field its "creativity and vitality" (Meine, 2010). Moving forward, an equally introspective and inclusive discussion on the normative dimensions of conservation paleobiology should be a high priority.

\section{AUTHOR CONTRIBUTIONS}

The author confirms being the sole contributor of this work and approved it for publication. 


\section{REFERENCES}

Barry, D., and Oelschlaeger, M. (1996). A science for survival: values and conservation biology. Conserv. Biol. 10, 905-911.

Dietl, G. P., Kidwell, S. M., Burney, D. A., Brenner, M., Flessa, K. W., Jaskson, S. T., et al. (2015). Conservation paleobiology: leveraging knowledge of the past to inform conservation and restoration. Annu. Rev. Earth Planet. Sci. 43, 79-103. doi: 10.1146/annurev-earth-040610133349

Hunter, M. L. Jr., Reford, K. H., and Lindenmayer, D. B. (2014). The complementary niches of anthropocentric and biocentric conservationists. Conserv. Biol. 28, 641-645. doi: 10.1111/cobi. 12296

Kareiva, P., and Marvier, M. (2012). What is conservation science? Bioscience 62, 962-969. doi: 10.1525/bio.2012.62.11.5

Lovejoy, T. (1989). The obligations of a biologist. Conserv. Biol. 3, 329-330.

Meine, C. (2010). "Conservation biology: present and past," in Conservation Biology for All, eds N. S. Sodhi and P. R. Erhlich (Oxford: Oxford University Press), 7-26.
Robinson, J. G. (2010). Ethical pluralism, pragmatism, and sustainability in conservation practice. Biol. Conserv. 144, 958-965. doi: 10.1016/j.biocon.2010.04.017

Soule, M. E. (1985). What is conservation biology? Bioscience 35, 727-734.

Tallis, H., and Lubchenco, J. (2014). A call for inclusive conservation. Nature 515, 27-28. doi: 10.1038/515027a

Van Dyke, F. (2008). Conservation Biology: Foundations, Concepts, Applications. New York, NY: Springer Science and Business Media.

Conflict of Interest Statement: The author declares that the research was conducted in the absence of any commercial or financial relationships that could be construed as a potential conflict of interest.

Copyright (C) 2016 Dietl. This is an open-access article distributed under the terms of the Creative Commons Attribution License (CC BY). The use, distribution or reproduction in other forums is permitted, provided the original author(s) or licensor are credited and that the original publication in this journal is cited, in accordance with accepted academic practice. No use, distribution or reproduction is permitted which does not comply with these terms. 